\title{
Auxin transport during root gravitropism: transporters and techniques
}

\author{
M. Geisler, B. Wang \& J. Zhu \\ Department of Biology - Plant Biology, University of Fribourg, Fribourg, Switzerland
}

\section{Keywords}

ABC transporters; chemiosmotic model; Cholodny-Went hypothesis; gravity sensing; IAA; PIN proteins.

\section{Correspondence}

M. Geisler, Department of Biology - Plant Biology, University of Fribourg, $\mathrm{CH}-1700$

Fribourg, Switzerland.

E-mail: markus.geisler@unifr.ch

\begin{abstract}
Root gravitropism is a complex, plant-specific process allowing roots to grow downward into the soil. Polar auxin transport and redistribution are essential for root gravitropism. Here we summarise our current understanding of underlying molecular mechanisms and involved transporters that establish, maintain and redirect intercellular auxin gradients as the driving force for root gravitropism. We evaluate the genetic, biochemical and cell biological approaches presently used for the analysis of auxin redistribution and the quantification of auxin fluxes. Finally, we also discuss new tools that provide a higher spatial or temporal resolution and our technical needs for future gravitropism studies.
\end{abstract}

\section{POLAR AUXIN TRANSPORT IS THE DRIVING FORCE FOR ROOT GRAVITROPISM}

Plant growth and development is influenced by many environmental factors, which lead to directional plant growth processes, such as gravitropism, phototropism and thigmotropism (Blancaflor \& Masson 2003). Gravitropism is controlled by gravity stimuli, which guide the emerging roots to grow downward into the soil and the shoots to grow upward (Friml \& Palme 2002).

The Cholodny-Went hypothesis suggested that root bending is caused by altered redistribution of auxin during root gravitropism (Went 1974). Work in the last three decades has provided solid evidence that cell-to-cell or polar auxin transport (PAT) is sufficient to generate differential intercellular auxin gradients that guide root growth (Rashotte et al. 2000). In vertically orientated roots, root-ward auxin transport is thought to provide equal auxin gradients on all sides of the root (Fig. 1A). However, in horizontally orientated roots, auxin is redirected and transported more efficiently at the lower side, resulting in an unequal, basipetally enhanced auxin distribution, and thus a steeper auxin gradient at the lower side (Fig. 1B). This is thought to inhibit cell elongation at the lower side of the root, resulting in downward growth of roots, although underlying mechanism are far from being understood. For example, at the lower side, according to the acid growth theory (Rayle et al. 1970; Hager et al. 1971; Rayle \& Zenk 1973), auxin-exposed cells are expected to excrete protons into the cell wall (apoplast), which are thought to activate cell wall loosening processes, forming the basis for cell elongation. Obviously, this is in contrast to the actual requirements, as cell wall loosening would be needed preferentially at the upper side. Accordingly, several aspects of the acid growth theory have received severe criticism (Rayle \& Cleland 1992).

However, there are several lines of hard evidence supporting the concept that PAT is the major driving force for root gravitropism. First, radiolabelled IAA was applied to measure the asymmetric redistribution of auxin. In horizontally orientated roots, labelled IAA moved downward across the root cap (Young et al. 1990). Second, immunolocalisation of IAA was used to visualise local auxin distribution in roots (see Fig. 2D; Shi et al. 1993; Benková et al. 2003; Schlicht et al. 2006). Third, the asymmetric redistribution of auxin was confirmed through the imaging of auxin reporter genes (Fig. 2). The auxin-responsive element DR5, fused to $\beta$-glucuronidase (GUS; Ulmasov et al. 1997) or to fluorescent proteins (e.g., GFP; Ottenschläger et al. 2003), was shown to be an indirect reporter of auxin accumulation in plant cells (reviewed in Muday \& DeLong 2001; Palme et al. 2006; Michniewicz et al. 2007). In horizontally orientated roots, DR5:GUS (or DR5:GFP) signals accumulate at the lower sides of the root, indicating higher auxin fluxes at these sides (Rashotte et al. 2001; Michniewicz et al. 2007; Muday \& Rahman 2008; Fig. 1B). These results were recently confirmed using a novel, independent Aux/IAA-based auxin signalling sensor, called DII-VENUS, (Brunoud et al. 2012; Band et al. 2012; Fig. 2C; for more details, see below). Use of DII-VENUS revealed that auxin is redistributed within minutes to the lower side of the root after the gravity stimulus. Unexpectedly, auxin asymmetry was rapidly lost when bending root tips reached an angle of $40^{\circ}$ to the horizontal; however, the physiological relevance of this so-called 'tipping point' mechanism is as yet unclear (Band et al. 2012). 

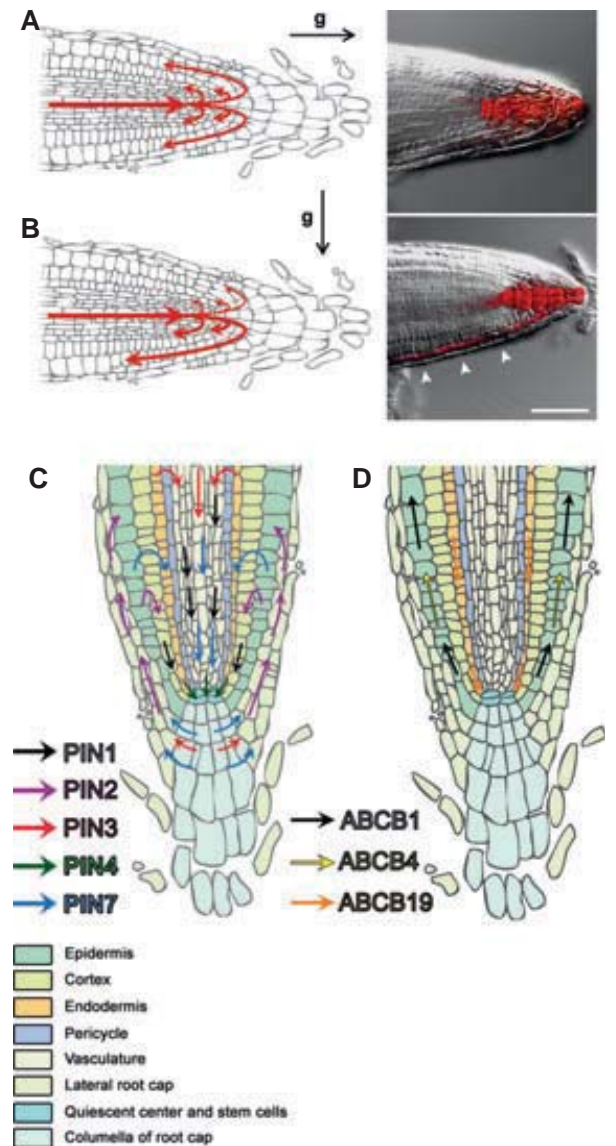

Fig. 1. Auxin gradients are shoot-ward redirected by PIN and ABCB-type auxin transporters upon gravi-stimulation. A, B: Even distribution of the auxin-responsive reporter DR5:GFP (red) in vertically grown Arabidopsis seeds (A) DR5:GFP expression is elevated at the lower side of gravistimulated roots inhibiting cell elongation, which results in root bending. Arrowheads indicate elevated DR5:GFP expression in the lateral root cap; bar $=50 \mu \mathrm{m}$. C, D: Reflux and long-range auxin transport networks provided by members of the PIN (C) and ABCB (D) family.

Finally, work from the Muday lab showed clearly that inhibition of basipetal/shoot-ward IAA transport after local application of low concentrations of the auxin efflux inhibitor NPA (1-N-naphthylphthalamic acid; see below for details) blocked the gravity response. In contrast, inhibition of acropetal/rootward IAA transport after application of NPA at the root-shoot junction only partially reduced the gravity response, and high NPA concentrations were needed to do so (Rashotte et al. 2000). This pharmacological work was confirmed genetically; the pin2/eir1 mutant exhibited reduced basipetal IAA transport and wild-type levels of acropetal IAA transport, but agravitropic roots. In summary, these results suggest that basipetally/ shoot-ward transported IAA controls root gravitropism in Arabidopsis.

\section{AUXIN TRANSPORTERS GENERATE, MAINTAIN AND CONTROL INTERCELLULAR AUXIN GRADIENTS ESSENTIAL FOR ROOT GRAVITROPISM}

The chemiosmotic model (Rubery \& Sheldrake 1973; Raven 1975; Goldsmith \& Goldsmith 1977) proposed that
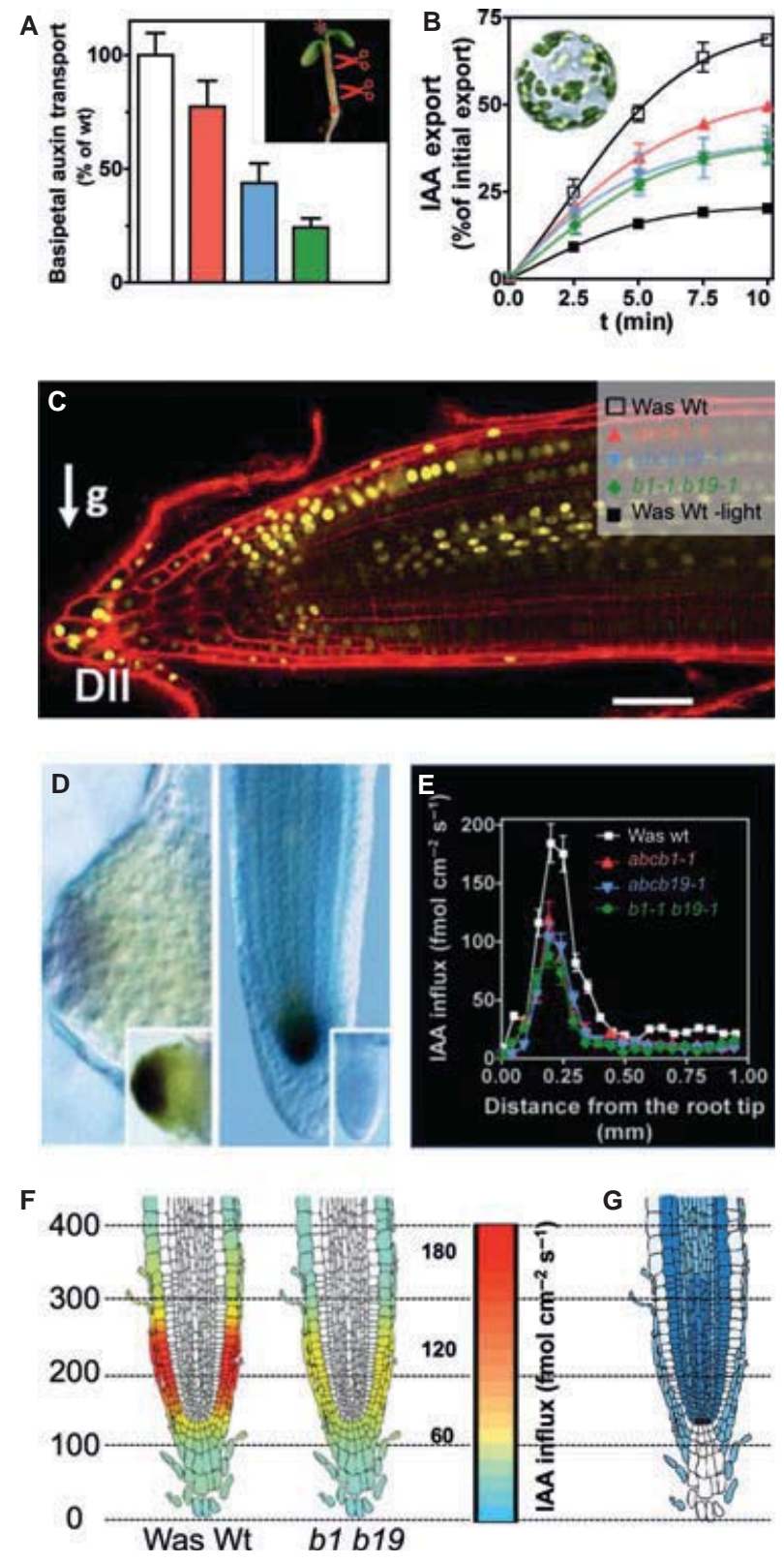

Fig. 2. Techniques for quantifying auxin concentrations and fluxes.A, B: Transport of radiolabelled IAA in Arabidopsis hypocotyls ( $A$ : inset describes principle of the assay) or mesophyll protoplasts ( $B$ : inset shows protoplast) is gradually reduced in abcb mutants (data from Geisler et al. 2003, 2005; for legend, see inset of C). C: DII-VENUS signal $2 \mathrm{~h}$ after a gravity stimulus in root tissues of wild-type Arabidopsis (bar $=50 \mu \mathrm{m}$, image taken from Band et al. 2012). D: Immunolocalisation of IAA reveals an IAA gradient with a maximum at the tip of the root primordium (left panel; inset shows increased signal after IAA treatment). IAA accumulation in the columella initial region of the mature lateral root (right panel; inset shows negative control in the absence of IAA fixation; image from Benková et al. 2003). E, F: Root IAA influx profiles measured with an IAA-specific microelectrode are altered in $a b c b$ mutants compared to Was wild type (data from Bailly et al. 2008 and Wang et al. 2013). Graphic (E) and heat map (F) presentation of influx profiles (see Wang et al. 2013 for details; lines mark distance from root tip in $\mu \mathrm{m}$, and tissues are indicated in Fig. 1D). G: High-resolution auxin distribution map as analysed with a combination of FACS of GFP-marked cell types and GC-MS (data from Petersson et al. 2009). Note low resolution for epidermal layers in comparison to electrode data in (F). 
intercellular IAA movement is facilitated by combined activities of auxin influx and efflux transporters. The sometimesneglected reason is simple and based on the fact that IAA is a weak acid $\left(\mathrm{pK}_{\mathrm{a}}\right.$ 4.75). Therefore most of the IAAH (roughly $85 \%$ ) is deprotonated to $\mathrm{IAA}^{-}$and thus is trapped in the cytoplasm at a $\mathrm{pH}$ of $c a$. 7.0, requiring auxin efflux transporters (Zažímalová et al. 2009). Moreover, also at apoplastic pH of ca. 5.5 , only a small portion of IAAH (roughly $15 \%$ ) is able to passively diffuse inside the cell, arguing for active uptake systems. However, the fact that a reasonable amount of IAAH can still enter cells through diffusion necessitates exporters as the primary control units of PAT.

Genetic and biochemical approaches have identified members of the AUX1/LAX (AUXIN-INSENSITIVE1/LIKE AUX1), PIN (PIN-FORMED) and ABCB (B subfamily of ABC transporters) families that play essential roles during polar auxin transport, and thus root gravitropism. Polarity of auxin transport is thought to require asymmetric localisations of auxin transporters, which mainly holds true for members of the PIN and also for AUX1, but ABCBs mostly have non-polar locations (Geisler \& Murphy 2006).

Transporters of other classes, such as PILS (PIN-LIKE PROTEINS; Barbez et al. 2012; Rosquete et al. 2012), ABCGs (Ruzicka et al. 2010) and NRT1.1 (Krouk et al. 2010), also seem to catalyse the transport of auxins; however, their role in root gravitropism is less clear.

The auxin influx carrier, AUX1, first identified in an screen for resistance to the synthetic auxin 2.4-D (Maher \& Martindale 1980) was suggested to regulate root gravitropism, since its mutant, auxl, shows a strong agravitropic root phenotype (Bennett et al. 1996). Arabidopsis has three more AUX1-like auxin importers: LAX1-3 importers, belonging to a plantspecific subclass of the amino acid/auxin permease (AAAP) super family, which perform distinct developmental functions and have evolved distinct regulatory mechanisms. Both AUX1 and LAX3 have been implicated in lateral root (LR) development, as well as apical hook formation, whereas both AUX1 and LAX1 are required for phyllotactic leaf patterning (Swarup \& Péret 2012). However, in comparison to AUX1, the individual impact of LAX1-3 on root gravitropism is less clear (Swarup et al. 2008; Péret et al. 2012).

In Arabidopsis, PIN proteins are encoded by a small gene family having eight members (Grunewald \& Friml 2010). So-called long-looped PIN proteins (PIN1, 2, 3, 4, 7; Fig. 1) are localised on the plasma membrane and are key components for intercellular and intracellular auxin movement (Fig. 1C), while short-looped PINs (PIN5, 6, 8) are thought to reside on the $\mathrm{ER}$, and thus play a role in the regulation of auxin homeostasis (Mravec et al. 2009; Dal Bosco et al. 2012; Ding et al. 2012).

PIN1 was the first auxin efflux carrier protein identified, originally described to function in shoot-to-root auxin transport, based on its basal/root-ward location in the xylem parenchyma (Okada et al. 1991; Gälweiler et al. 1998). Later, PIN1 was also localised to the root stele, where it also predominantly reveals basal/root-ward localisation (Friml \& Palme 2002; Fig. 1C). PIN2/AGR1/EIR1/WAV6 localises shoot-ward in the lateral root cap and root epidermis cells, and root-ward in the root cortex cells (Chen et al. 1998; Luschnig et al. 1998; Muller et al. 1998; Utsuno et al. 1998). Therefore, shoot-ward auxin distribution in the lower side of the root is largely repressed in the pin 2 mutant during gravity stimulus, thus resulting in agra- vitropism. Additionally, PIN2 was found at the root-ward face of cortical cells of the meristem, and is thus thought be involved in an auxin reflux loop (Blilou et al. 2005; Wisniewska et al. 2006; Rahman et al. 2010; Fig. 1C).

PIN3 is thought to link gravity perception and lateral auxin redistribution in root gravitropism (reviewed in Michniewicz et al. 2007). PIN3 is expressed in gravity-sensing tissues, where it mainly localises uniformly in the columella cell boundaries (Friml et al. 2002). More importantly, during a gravity stimulus, PIN3 relocates to the new lower side of the columella cells, thus correlating with a downward redirection of auxin flows, which suggests that PIN3 functions in redirecting auxin fluxes to trigger asymmetric growth. PIN4 and PIN7 have partially overlapping functions with other PINs in the root tip (Fig. 1C), although their involvement in root gravitropism is less clear (Grunewald \& Friml 2010).

In light of its important role in root-ward auxin transport, the absence of an obvious root phenotype for pin1 mutants and its rather intact root bending is remarkable. In principle, the same holds true for pin 3 mutants that also reveal very mild gravitropic root defects (Friml et al. 2002). With the exception of the PIN2 mutant, only multiple PIN loss-of function mutants show severe gravitropic deficiencies, arguing, in light of the low degree of obvious co-location or functional redundancy between PIN isoforms (Fig. 1C), for other auxin transporters that are able to take over, at least partially, their functions.

Full-length $\mathrm{ABC}$ transporters of the $\mathrm{B}$ subclass, e.g., $\mathrm{ABCB} 1$ (PGP1), ABCB19 (PGP19/MDR1) and ABCB4 (PGP4), are involved in root gravitropism, as abcb1 abcb19, and abcb4 mutants show significantly reduced gravitropic responses (Noh et al. 2001; Santelia et al. 2005; Terasaka et al. 2005; Bouchard et al. 2006; Bailly et al. 2008; Fig. 1D). Bending defects in $A B C B 1$ and $A B C B 19$ single mutants are subtle, which is in line with their demonstrated functional redundancy (Geisler et al. 2005; Bailly et al. 2008); however, they reveal altered early bending kinetics (Bailly et al. 2008). Root bending defects correlate with gradually reduced auxin efflux, transport and gradient capacities (Geisler et al. 2005; Bouchard et al. 2006; Bailly et al. 2008; Fig. 2). The direct involvement of ABCBmediated auxin transport in PAT, and thus in root gravitropism, suggests that polar locations of these transporters are not an absolute requirement because $\mathrm{ABCB} 1,4$ and 19 show only a low degree of cellular polarity (Geisler et al. 2005; Terasaka et al. 2005; Mravec et al. 2009). Vectorial auxin transport by $\mathrm{ABCBs}$ might therefore involve functional interaction with other $\mathrm{ABCB}$ interacting components, such as PINs (Blakeslee et al. 2007) or TWISTED DWARF1 (TWD1; Geisler et al. 2003; Bailly et al. 2008; Wu et al. 2010; Wang et al. 2013), revealing them as having a higher degree of polarity. A current study suggests that lateral auxin transport into the epidermal apoplast might be specifically triggered by plasma membrane interactions between non-polar ABCB1 and laterally expressed TWD1 (Wang et al. 2013).

In summary, it appears that $\mathrm{ABCB}$ expression and functionality correlates with small meristematic cells with high auxin content, where they function in avoiding apoplastic reflux (Wang et al. 2013). Nevertheless, they still function in longrange transport of auxin, as the described $a b c b$ mutants show defects in their content (Geisler et al. 2005; Geisler \& Murphy 2006; Matsuda et al. 2011; Fig. 1D). 
Interestingly, $\mathrm{ABCB} 4$ and its closest homologue, $\mathrm{ABCB} 21$ (Kamimoto et al. 2012), have recently been demonstrated to function as facultative IAA importers/exporters triggered by cytoplasmic auxin concentrations (Kamimoto et al. 2012; Kubeš et al. 2012). Import directionalities under low cytoplasmic IAA concentrations suggest a functional overlap with AUX1/LAX importers; however, in contrast to ABCB-PIN interactions, no such functional analogy has been found between tested ABCBs and AUX1 (Blakeslee et al. 2007).

Auxin transport inhibitors, with NPA being the most wildly used, have been successfully employed for demonstrating that polar auxin transport forms the basis of root gravitropism (Rashotte et al. 2000; see above). NPA, a non-competitive auxin efflux inhibitor, prevents the asymmetric distribution of DR5 signals and root gravitropism (Rashotte et al. 2001; Bailly et al. 2008). ABCB1, ABCB4 and ABCB19 proteins were identified as high-affinity NPA-binding site-associated proteins (Murphy et al. 2002; Geisler et al. 2003; Terasaka et al. 2005), and ABCB-mediated auxin efflux is NPA-sensitive (Geisler et al. 2005; Kim et al. 2010; Kamimoto et al. 2012). This suggests that NPA binds ABCBs directly, or/and other proteins, to inhibit $\mathrm{ABCB}$-driven auxin transport, thus affecting root gravitropism. A good candidate to convert an NPA effect on ABCBs is TWD1, which itself was shown to bind NPA (Bailly et al. 2008). Further, NPA was shown to disrupt TWD1ABCB1 interaction (Bailly et al. 2008). The findings that PIN proteins most probably do not bind NPA or the related inhibitor BUM (Kim et al. 2010), nor are they directly inhibited by $\mathrm{NPA}$ in an ABCB-free system, support further functional $\mathrm{ABCB}-\mathrm{PIN}$ interactions.

\section{TECHNIQUES FOR QUANTIFYING AUXIN CONCENTRATIONS AND FLUXES}

\section{Radiolabelled auxins}

The measurement of auxin concentrations and fluxes gives us direct clues to auxin transport and auxin distribution in plant organs, which helps us better understand the role of auxin transport in gravitropism.

Initially, radiolabelled auxins, such as ${ }^{3} \mathrm{H}$-IAA, were demonstrated to be very sensitive and reliable tools for auxin flux measurement at cellular and tissue levels. For example, more than 30 years ago, ${ }^{3} \mathrm{H}$-IAA was applied to study acropetal auxin transport in the central cylinder of the root and basipetal auxin transport in epidermal and cortical cells (Mitchell \& Davies 1975; Tsurumi \& Ohwaki 1978). The Murphy lab further increased the resolution of these techniques using microscope-guided micromanipulators that allow application of micro-droplets of IAA smaller than $0.1 \mu \mathrm{l}$ (Fig. 2A). Lewis \& Muday (2009) also provided widely used protocols for the measurement of auxin transport in roots, hypocotyls and inflorescences, where radiolabelled auxin is applied to seedlings in an agar cylinder or as droplets, which requires no specialised equipment.

A breakthrough in the verification and characterisation of auxin transporters was the establishment of protocols that allowed the quantification of auxin fluxes from cellular systems, such as plant mesophyll protoplasts, yeast cells, HeLa cells or BY-2 cells (Geisler et al. 2005; Petrášek et al. 2006; Yang $\&$ Murphy 2009). Despite the evolutionary origin of each cell type, each having individual (dis)advantages, cells are usually first loaded with radiolabelled auxins, and benzoic acid is often used as a negative (diffusion) control. Subsequently, loading can be stopped using gradient centrifugation (protoplasts) or vacuum filtration (yeast), and exported or imported auxin can be quantified through scintillation counting ('loading assay'). Alternatively, non-loaded auxin can be removed, and exported auxin can be quantified through a second centrifugation/filtration step that separates cells from the supernatant ('export assay'; Fig. 2B). Both assays work best when plasma membrane transporters are used; however, intra-membrane (ER) auxin transporters have also been successfully analysed following these protocols (Mravec et al. 2009; Ding et al. 2012).

A limitation of these assays is that with the exception of strict importer characterisations (such as AUX1/LAX transporters), whole-cell analyses do not allow for transport kinetics because the amount of cytoplasmic auxin cannot be adjusted due to secondary effects such as metabolisation and conjugation. Arguments in favour are that yeast, HeLa and protoplasted plant cells allow heterologous expression of transporters and regulatory components, which has permitted the characterisation of TWD1-ABCB1 (Bouchard et al. 2006; Bailly et al. 2008; Henrichs et al. 2012), ABCB-PIN (Blakeslee et al. 2007) and TWD1-ABCB1PID interactions (Henrichs et al. 2012).

In summary, the use of radiolabelled auxin allows for very sensitive, fast and highly reproducible quantification of auxin transport rates. However, it is obviously an invasive method that does not yet allow following the imaging of PAT at a reasonably high resolution. Moreover, the short-term application of auxin radiotracers might alter endogenous IAA homeostasis in the cells, even though the concentrations of auxin radiotracers can be kept extremely low (nanomolar to picomolar).

\section{Auxin response reporters and sensors}

As already discussed above, variants of auxin response reporters, like DR5 (Ulmasov et al. 1997), IAA2 (Abel et al. 1994) or BA3 (Armstrong et al. 2004), fused to reporter genes, such as GUS, GFP or RFP, are widely used as indirect markers for auxin concentrations and distribution patterns in Arabidopsis and other plants (Fig 1A; Ulmasov et al. 1997; Rashotte et al. 2001; Ottenschläger et al. 2003; Benková et al. 2003; Barbez et al. 2012). The most commonly used DR5:GFP construct (Ottenschläger et al. 2003) allows non-invasive, high spatial and temporal observations of DR5 expression in plant tissues and DR5 redistribution during gravitropism (Fig. 1A and B).

The limitation of all these reporters is that they represent indirect measures of auxin accumulation, and that DR5 expression is affected by the rates of its own transcription and translation (Band et al. 2012). As a result, the asymmetry of DR5 expression could only be detected for $1.5-2.0 \mathrm{~h}$ after gravity stimulation (Ottenschläger et al. 2003; Brunoud et al. 2012), making it far too slow to follow auxin distribution in real-time during root gravitropism, which usually takes place in minutes. Moreover, these auxin-responsive reporters are not absolutely specific for IAA. For example, the DR5 reporter is also activated by brassinolides, and even requires brassinolides to reach maximum activity (Nemhauser et al. 2004). Further, it seems as if DR5 has its limitations in other tissues with lower auxin concentrations, such as the hypocotyls or stems. Finally, the three 
most often used auxin-responsive promoters mentioned above show distinct expression patterns (Schlicht et al. 2006). For instance, the DR5 reporter shows maximum activity in the root cap columella and quiescent centre cells, whereas the BA3 has its maximum in rapidly elongating root cells.

Recently, a novel auxin signalling sensor, DII-VENUS, was engineered to map auxin responses and distribution. Monitoring DII-VENUS degradation was thought to be better as an auxin sensor because its signal is linked more directly to hormone abundance compared to translational reporters. DIIVENUS is AUX-/IAA-based, and thus has earlier IAA responses in the auxin signalling pathway compared to DR5 (Band et al. 2012; Brunoud et al. 2012). As a result, the asymmetry of DII-VENUS degradation can be detected within $30 \mathrm{~min}$ after gravity stimulation (Fig. 2C). Although DII-VENUS provides high-resolution spatio-temporal information on IAA distribution, it still cannot detect absolute IAA accumulation within cells and tissues. Another issue with the so far presented promoter elements or sensors is that, due to their signalling concept, they are unable to directly monitor intra- and extracellular auxin concentrations.

\section{Auxin immunodetection}

The original protocols successfully used IAA antisera for IAA immunodetection in primary and lateral roots that were directed against IAA after IAA fixation (Caruso et al. 1995; Benková et al. 2003; Fig. 2D). However, despite the fact that the IAA accumulation pattern essentially resembled the DR5 activity pattern, this method somehow never reached a high level of acceptance within the community. This is most likely because IAA antibodies used in these studies were not shown to be mono-specific and might therefore cross-react with IAA precursors, such as tryptophan. Moreover, cross-linking agents used for IAA immobilisation are thought to have drastic effects on actin organisation, and thus alter PAT prior to fixation (Schlicht et al. 2006). Therefore novel, highly specific auxin antibodies, recognising essentially only IAA, have been developed by research groups (Schlicht et al. 2006) and commercial companies (Agrisera AB, Vännäs, Sweden). However, these are so far mainly used for ELISA tests and rarely for immunolocalisation, probably because the resulting accumulation patterns are distinct from DR5 signals (Schlicht et al. 2006).

\section{Auxin-specific microelectrodes}

A platinum microelectrode modified from carbon nanotubes was developed at the Mancuso lab for non-invasive and continuous recordings of auxin fluxes in intact root apices (Fig. 2E-F; Mancuso et al. 2005). In this method, a vibrating, self-referencing microelectrode that is highly specific for IAA is applied close to the root surface at different distances from the apex (vibrating distance $10 \mu \mathrm{m}$ at $0.1 \mathrm{~Hz}$ ), and the differential electronic signals are recorded and calculated. The free IAA indirectly determined using this method was close to that quantified with HPLC (Mancuso et al. 2005). This method, originally developed for maize, has been successfully employed to record IAA influxes from Arabidopsis roots, and IAA influx peaks are typically found around $200 \mu \mathrm{m}$ from the root tip of wild-type plants (Santelia et al. 2005; Bailly et al. 2008; Kim et al. 2010; Henrichs et al. 2012; Wang et al. 2013; Fig. 2E), consistent with the current auxin 'reflux model' (see Fig. 1C; Blilou et al. 2005). The combination of IAA influx data and confocal root pictures has allowed better presentation of epidermal IAA influx rates (Wang et al. 2013; Fig. 2F). In between several auxin transport mutants (Santelia et al. 2005; Bouchard et al. 2006; Bailly et al. 2008; Wan et al. 2012) and PAT inhibitors, including NPA (Bailly et al. 2008; McLamore et al. 2010), BUM (Kim et al. 2010) and quercetin/chelerytrine (Henrichs et al. 2012) have been successfully characterized using this method.

Obvious advantages of this highly sensitive method are that it is able to monitor local IAA concentrations continuously and non-invasively in living plants, which also allows researchers to follow the effect of externally applied drugs, as described above. However, this method only allows for a high-resolution measurement of epidermal layers, making it complementary to FACS-based methods (Petersson et al. 2009; see below), but making it unsuitable for investigation of other cell files (Fig. 2F). Another valid drawback is that during IAA influx recording, roots are exposed to high external IAA concentrations. Finally, while this assay can be carried out under different light conditions, it does not allow the measurement of auxin fluxes during root bending.

\section{Determination of free IAA}

The concentration of endogenous free IAA from different plant tissues or segments can be precisely determined with gas chromatography-mass spectrometry (GC-MS), usually carried out after methanol extraction (Pollmann et al. 2002). For quantification with a state-of-the-art GC-MS, as little as $10 \mathrm{mg}$ fresh weight tissue is now needed, corresponding to $c a .30$ seedlings. However, recent progress in HPLC/GC-MS/MS coupling (high-pressure liquid chromatography in combination with gas chromatography-tandem mass spectrometry) is expected to further reduce the amount of starting material required. Calculation of isotopic dilution factors is usually based on the addition of radiolabelled markers, such as ${ }^{13} \mathrm{C}$-IAA or ${ }^{2} \mathrm{H}$-IAA.

The content of free IAA from different Arabidopsis and tobacco tissues can be measured with ELISA using monospecific IAA antisera, and several ELISA-based kits are on the market. Despite some initial criticism (Cohen et al. 1987), ELISA data have been shown to match HPLC validations (Chen \& Zhao 2008), and might turn out to be a low-cost alternative.

A combination of fluorescence-activated cell sorting (FACS) of GFP-marked cell types and GC-MS was recently used to construct a high-resolution auxin distribution map (Fig. 2G; Petersson et al. 2009). In short, root protoplasts were isolated from different Arabidopsis GFP-marked cell lines and quantified with coupled gas chromatography-selected reaction mode-mass spectrometry (GC-SRM-MS). IAA concentrations were normalised by cell number and cell size. Compared to the above-described reporter or sensor tools, this method gives a direct quantification of intracellular IAA concentrations. It can also be used in high-throughput mode, and genome-wide transcriptional changes of auxin-responsive factors were recently described with a comparable FACS technique (Bargmann \& Birnbaum 2009). The limitation of this method is that only steady-state levels of IAA are quantified because auxin concentrations are equally annotated in cells from the same cell type. Further, the resolution of the epidermal layer is still poor, 
which might be improved using more specific cell type marker lines in the future.

\section{PERSPECTIVES}

Polar auxin transport and the redistribution of auxin are essential for root gravitropism, and thus also for human nutrition. However, despite substantial progress, our understanding of underlying mechanisms is still incomplete, in part due to technical limitations. Hence, there is an obvious need for novel, innovative genetic, biochemical and cellular biology approaches for the analysis of auxin fluxes having higher temporal and spatial resolution.

Within the auxin community there is an obvious consensus that a high-resolution, non-invasive auxin biosensor for the quantification of cytoplasmic (and preferably also apoplastic) IAA concentrations is absolutely essential. Obviously, such a genetically encoded biosensor would most probably also allow real-time imaging of auxin fluxes during root gravitropism. Biosensors for the measurement of cations, such as calcium (Cameleon; Miyawaki et al. 1999) and for protons (pHusion; Gjetting et al. 2012) have been found to be very useful for in vivo, non-invasive studies of ion fluxes in cells. While $\mathrm{pH}$ sensors usually employ the $\mathrm{pH}$ sensitivity of EGFP, a future IAA biosensor would also probably be FRET-based, in analogy to the calcium sensor, cameleon (Allen et al. 1999). A possible complication might be the fact that concentrations of free IAA diverge in different tissues, thus eventually requiring a range of sensors, each with a different IAA affinity.

Further, the development of chemically modified auxin analogues has potential for cellular IAA distribution analysis. Recently, alkoxy-auxins, such as 5-alkoxy-IAA and 7-alkoxyNAA, were shown not to alter auxin-responsive gene expression mediated by the TIR1 pathway, but inhibited polar auxin transport streams and auxin-dependent tropic responses in maize and Arabidopsis (Tsuda et al. 2011). Very recently, at the Auxin2012 conference (http://auxin.hawaiiconference.com), for the first time fluorescent IAA and NAA analogues were presented by the Hayashi group (Hayashi 2012), which could potentially fill the gap until we have a genetic biosensor.

\section{ACKNOWLEDGEMENTS}

We thank our colleagues from the auxin transport community for advancing this exciting discipline, and A. Bailly for providing artwork. This work was supported by grants from the Novartis Foundation (to M.G), from the Pol de Recherche of the University of Fribourg (to M.G.) and from Swiss National Funds (to M.G.).

\section{REFERENCES}

Abel S., Oeller P.W., Theologis A. (1994) Early auxininduced genes encode short-lived nuclear proteins. Proceedings of the National Academy of Sciences of the United States of America, 91, 326-330.

Allen G.J., Kwak J.M., Chu S.P., Llopis J., Tsien R.Y., Harper J.F., Schroeder J.I. (1999) Cameleon calcium indicator reports cytoplasmic calcium dynamics in Arabidopsis guard cells. The Plant Journal, 19, 735-747.

Armstrong J.I., Yuan S., Dale J.M., Tanner V.N., Theologis A. (2004) Identification of inhibitors of auxin transcriptional activation by means of chemical genetics in Arabidopsis. Proceedings of the National Academy of Sciences of the United States of America, 101, 14978-14983.

Bailly A., Sovero V., Vincenzetti V., Santelia D., Bartnik D., Koenig B.W., Mancuso S., Martinoia E., Geisler M. (2008) Modulation of P-glycoproteins by auxin transport inhibitors is mediated by interaction with immunophilins. Journal of Biological Chemistry, 283, 21817-21826.

Band L.R., Wells D.M., Larrieu A., Sun J., Middleton A.M., French A.P., Brunoud G., Sato E.M., Wilson M.H., Péret B., Oliva M., Swarup R., Sairanen I., Parry G., Ljung K., Beeckman T., Garibaldi J.M., Estelle M., Owen M.R., Vissenberg K., Hodgman T.C., Pridmore T.P., King J.R., Vernoux T., Bennett M.J. (2012) Root gravitropism is regulated by a transient lateral auxin gradient controlled by a tippingpoint mechanism. Proceedings of the National Academy of Sciences of the United States of America, 109, 4668-4673.

Barbez E., Kubeš M., Rolčík J., Béziat C., Pěnčík A., Wang B., Rosquete M.R., Zhu J., Dobrev P.I., Lee Y., Zažímalovà E., Petrášek J., Geisler M., Friml J., Kleine-Vehn J. (2012) A novel putative auxin carrier family regulates intracellular auxin homeostasis in plants. Nature, 485, 119-122.
Bargmann B.O., Birnbaum K.D. (2009) Positive fluorescent selection permits precise, rapid, and in-depth overexpression analysis in plant protoplasts. Plant Physiology, 149, 1231-1239.

Benková E., Michniewicz M., Sauer M., Teichmann T., Seifertová D., Jürgens G., Friml J. (2003) Local, efflux-dependent auxin gradients as a common module for plant organ formation. Cell, 115, 591-602.

Bennett M.J., Marchant A., Green H.G., May S.T., Ward S.P., Millner P.A., Walker A.R., Schulz B., Feldmann K.A. (1996) Arabidopsis AUX1 gene, a permease-like regulator of root gravitropism. Science, 273, 948-950.

Blakeslee J.J., Bandyopadhyay A, Lee O.R., Mravec J., Titapiwatanakun B., Sauer M., Makam S.N., Cheng Y., Bouchard R., Adamec J., Geisler M., Nagashima A., Sakai T., Martinoia E., Friml J., Peer W.A., Murphy A.S. (2007) Interactions among PIN-FORMED and P-glycoprotein auxin transporters in Arabidopsis. The Plant Cell, 19, 131-147.

Blancaflor E.B., Masson P.H. (2003) Plant gravitropism. Unraveling the ups and downs of a complex process. Plant Physiology, 133, 1677-1690.

Blilou I., Xu J., Wildwater M., Willemsen V., Paponov I., Friml J., Heidstra R., Aida M., Palme K., Scheres B. (2005) The PIN auxin efflux facilitator network controls growth and patterning in Arabidopsis roots. Nature, 433, 39-44.

Bouchard R., Bailly A., Blakeslee J.J., Oehring S.C., Vincenzetti V., Lee O.R., Paponov I., Palme K., Mancuso S., Murphy A.S., Schulz B., Geisler M. (2006) Immunophilin-like TWISTED DWARF1 modulates auxin efflux activities of Arabidopsis P-glycoproteins. Journal of Biological Chemistry, 281, 30603-30612.

Brunoud G., Wells D.M., Oliva M., Larrieu A., Mirabet V., Burrow A.H., Beeckman T., Kepinski S., Traas J., Bennett M.J., Vernoux T. (2012) A novel sensor to map auxin response and distribution at high spatiotemporal resolution. Nature, 482, 103-106.
Caruso J., Pence V., Leverone L. (1995) Immunoassay methods of plant hormone analysis. In: Davies P.J. (Ed.), Plant Hormones: Physiology, Biochemistry and Molecular Biology. Kluwer Academic, Norwell, MA, USA, pp 433-447.

Chen D., Zhao J. (2008) Free IAA in stigmas and styles during pollen germination and pollen tube growth of Nicotiana tabacum. Physiologia Plantarum, 134, 202-215.

Chen R., Hilson P., Sedbrook J., Rosen E., Caspar T., Masson P.H. (1998) The Arabidopsis thaliana AGRAVITROPIC 1 gene encodes a component of the polar-auxin-transport efflux carrier. Proceedings of the National Academy of Sciences of the United States of America, 95, 15112-15117.

Cohen J.D., Bausher M.G., Bialek K., Buta J.G., Gocal G.F., Janzen L.M., Pharis R.P., Reed A.N., Slovin J.P. (1987) Comparison of a commercial ELISA assay for indole-3-acetic acid at several stages of purification and analysis by gas chromatography-selected ion monitoring-mass spectrometry using a c(6)-labeled internal standard. Plant Physiology, 84, 982-686.

Dal Bosco C., Dovzhenko A., Liu X., Woerner N., Rensch T., Eismann M., Eimer S., Hegermann J., Paponov I.A., Ruperti B., Heberle-Bors E., Touraev A., Cohen J.D., Palme K. (2012) The endoplasmic reticulum localized PIN8 is a pollen-specific auxin carrier involved in intracellular auxin homeostasis. The Plant Journal, 71, 860-870.

Ding Z., Wang B., Moreno I., Dupláková N., Simon S., Carraro N., Reemmer J., Pěnčík A., Chen X., Tejos R., Skůpa P., Pollmann S., Mravec J., Petrášek J., Zažímalová E., Honys D., Rolčík J., Murphy A., Orellana A., Geisler M., Friml J. (2012) ER-localized auxin transporter PIN8 regulates auxin homeostasis and male gametophyte development in Arabidopsis. Nature communications, 3, 941.

Friml J., Palme K. (2002) Polar auxin transport - old questions and new concepts? Plant Molecular Biology, 49, 273-284. 
Friml J., Wisniewska J., Benkova E., Mendgen K. Palme K. (2002) Lateral relocation of auxin efflux regulator PIN3 mediates tropism in Arabidopsis. Nature, 415, 806-809.

Gälweiler L., Guan C., Müller A., Wisman E., Mendgen K., Yephremov A., Palme K. (1998) Regulation of polar auxin transport by AtPIN1 in Arabidopsis vascular tissue. Science, 282, 2226-2230.

Geisler M., Murphy A.S. (2006) The ABC of auxin transport: the role of p-glycoproteins in plant development. FEBS Letters, 580, 1094-1102.

Geisler M., Kolukisaoglu H.U., Bouchard R., Billion K., Berger J., Saal B., Frangne N., Koncz-Kalman Z., Koncz C., Dudler R., Blakeslee J.J., Murphy A.S., Martinoia E., Schulz B. (2003) TWISTED DWARF1, a unique plasma membrane-anchored immunophilin-like protein, interacts with Arabidopsis multidrug resistance-like transporters AtPGP1 and AtPGP19. Molecular Biology of the Cell, 14, 4238-4249.

Geisler M., Blakeslee J.J., Bouchard R., Lee O.R., Vincenzetti V., Bandyopadhyay A., Titapiwatanakun B., Peer W.A., Bailly A., Richards E.L., Ejenda K.F.K., Smith A.P., Baroux C., Grossniklaus U., Muller A., Hrycyna C.A., Dudler R., Murphy A.S., Martinoia E. (2005) Cellular efflux of auxin catalyzed by the Arabidopsis MDR/PGP transporter AtPGP1. The Plant Journal, 44, 179-194.

Gjetting K.S., Ytting C.K., Schulz A., Fuglsang A.T. (2012) Live imaging of intra- and extracellular pH in plants using pHusion, a novel genetically encoded biosensor. Journal of Experimental Botany, $\mathbf{6 3}$, 3207-3218.

Goldsmith M., Goldsmith T. (1977) Chemisomotic model for polar transport of auxin. Plant Physiology, 59, 90-90.

Grunewald W., Friml J. (2010) The march of the PINs: developmental plasticity by dynamic polar targeting in plant cells. EMBO Journal, 29, 2700-2714.

Hager A., Menzel H., Krauss A. (1971) Versuche und Hypothese zur Primärwirkung des Auxins beim Streckungswachstum. Planta, 100, 47-75.

Hayashi K. (2012) Visualization of cellular auxin distribution by chemical biology approach. Abstract book of the AUXIN 2012 Conference, Hawai'i, USA $15 \mathrm{pp}$.

Henrichs S., Wang B., Fukao Y., Zhu J., Charrier L. Bailly A., Oehring S.C., Linnert M., Weiwad M., Endler A., Nanni P., Pollmann S., Mancuso S. Schulz A., Geisler M. (2012) Regulation of ABCB1/ PGP1-catalysed auxin transport by linker phosphorylation. EMBO Journal, 31, 2965-2980.

Kamimoto Y., Terasaka K., Hamamoto M., Takanashi K., Fukuda S., Shitan N., Sugiyama A., Suzuki H. Shibata D., Wang B., Pollmann S., Geisler M., Yazaki K. (2012) Arabidopsis ABCB21 is a Facultative Auxin Importer/Exporter Regulated by Cytoplasmic Auxin Concentration. Plant and Cell Physiology, 53, 2090-2100.

Kim J.Y., Henrichs S., Bailly A., Vincenzetti V., Sovero V., Mancuso S., Pollmann S., Kim D., Geisler M., Nam H.G. (2010) Identification of an ABCB/P-glycoprotein-specific inhibitor of auxin transport by chemical genomics. Journal of Biological Chemistry, 285, 23309-23317.

Krouk G., Lacombe B., Bielach A., Perrine-Walker F., Malinska K., Mounier E., Hoyerova K., Tillard P., Leon S., Ljung K., Zazimalova E., Benkova E., Nacry P., Gojon A. (2010) Nitrate-regulated auxin trans- port by NRT1.1 defines a mechanism for nutrient sensing in plants. Developmental Cell, 18, 927-937.

Kubeš M., Yang H., Richter G.L., Cheng Y., Młodzińska E., Wang X., Blakeslee J.J., Carraro N., Petrášek J., Zažímalová E., Hoyerová K., Peer W.A. Murphy A.S. (2012) The Arabidopsis concentrationdependent influx/efflux transporter ABCB4 regulates cellular auxin levels in the root epidermis. The Plant Journal, 69, 640-654.

Lewis D.R., Muday G.K. (2009) Measurement of auxin transport in Arabidopsis thaliana. Nature Protocols, 4, 437-451.

Luschnig C., Gaxiola R.A., Grisafi P., Fink G.R. (1998) EIR1, a root-specific protein involved in auxin transport, is required for gravitropism in Arabidopsis thaliana. Genes \& Development, 12, 2175-2187.

Maher E.P., Martindale S.J. (1980) Mutants of Arabidopsis thaliana with altered responses to auxins and gravity. Biochemical Genetics, 18, 1041-1053.

Mancuso S., Marras A.M., Magnus V., Baluska F. (2005) Noninvasive and continuous recordings of auxin fluxes in intact root apex with a carbon nanotube-modified and self-referencing microelectrode. Analytical Biochemistry, 341, 344-351.

Matsuda S., Kajizuka T., Kadota A., Nishimura T., Koshiba T. (2011) NPH3- and PGP-like genes are exclusively expressed in the apical tip region essential for blue-light perception and lateral auxin transport in maize coleoptiles. Journal of Experimental Botany, 62, 3459-3466.

McLamore E.S., Diggs A., Calvo Marzal P., Shi J., Blakeslee J.J., Peer W.A., Murphy A.S., Porterfield D.M. (2010) Non-invasive quantification of endogenous root auxin transport using an integrated flux microsensor technique. The Plant Journal, 63, 1004-1016.

Michniewicz M., Brewer P., Friml J. (2007) Polar auxin transport and asymmetric auxin distribution. In: The Arabidopsis Book. The American Society of Plant Biologists, Rockville, MA, USA, doi: 10.1199/tab. 0108 .

Mitchell E.K., Davies P.J. (1975) Evidence for three different systems of movement of indole acetic acid in intact roots of Phaseolus coccineus. Physiologia Plantarum, 33, 290-294.

Miyawaki A., Griesbeck O., Heim R., Tsien R.Y. (1999) Dynamic and quantitative $\mathrm{Ca}^{2+}$ measurements using improved cameleons. Proceedings of the National Academy of Sciences of the United States of America, 96, 2135-2140.

Mravec J., Skůpa P., Bailly A., Hoyerová K., Krecek P., Bielach A., Petrásek J., Zhang J., Gaykova V., Stierhof Y.D., Dobrev P.I., Schwarzerová K., Rolcík J., Seifertová D., Luschnig C., Benková E., Zazímalová E., Geisler M., Friml J. (2009) Subcellular homeo stasis of phytohormone auxin is mediated by the ER-localized PIN5 transporter. Nature, 459, 1136-1140.

Muday G.K., DeLong A. (2001) Polar auxin transport: controlling where and how much. Trends in Plant Science, 11, 535-542.

Muday G.K., Rahman A. (2008) Auxin transport and the integration of gravitropic growth. In: Gilroy S. Masson P.H. (Eds), Plant Tropisms. Blackwell, Ames, IA, USA, pp 47-77.

Muller A., Guan C., Galweiler L., Tanzler P., Huijser P., Marchant A., Parry G., Bennett M., Wisman E., Palme K. (1998) AtPIN2 defines a locus of Arabidopsis for root gravitropism control. EMBO Journal, 17 6903-6911.
Murphy A.S., Hoogner K.R., Peer W.A., Taiz L. (2002) Identification, purification, and molecular cloning of N-1-naphthylphthalmic acid-binding plasma membrane-associated aminopeptidases from Arabidopsis. Plant Physiology, 128, 935-950.

Nemhauser J.L., Mockler T.C., Chory J. (2004) Interdependency of brassinosteroid and auxin signaling in Arabidopsis. PLoS Biology, 2, E258.

Noh B., Murphy A.S., Spalding E.P. (2001) Multidrug resistance-like genes of Arabidopsis required for auxin transport and auxin-mediated development. The Plant Cell, 13, 2441-2454.

Okada K., Ueda J., Komaki M.K., Bell C.J., Shimura Y. (1991) Requirement of the Auxin Polar Transport System in Early Stages of Arabidopsis Floral Bud Formation. The Plant Cell, 3, 677-684.

Ottenschläger I., Wolff P., Wolverton C., Bhalerao R.P., Sandberg G., Ishikawa H., Evans M., Palme K. (2003) Gravity-regulated differential auxin transport from columella to lateral root cap cells. Proceedings of the National Academy of Sciences of the United States of America, 100, 2987-2991.

Palme K., Dovzhenko A., Ditengou F.A. (2006) Auxin transport and gravitational research: perspectives. Protoplasma, 229, 175-181.

Péret B., Swarup K., Ferguson A., Seth M., Yang Y., Dhondt S., James N., Casimiro I., Perry P., Syed A., Yang H., Reemmer J., Venison E., Howells C., PerezAmador M.A., Yun J., Alonso J., Beemster G.T., Laplaze L., Murphy A., Bennett M.J., Nielsen E., Swarup R. (2012) AUX/LAX genes encode a family of auxin influx transporters that perform distinct functions during Arabidopsis development. The Plant Cell, 24, 2874-2885.

Petersson S.V., Johansson A.I., Kowalczyk M., Makoveychuk A., Wang J.Y., Moritz T., Grebe M., Benfey P.N., Sandberg G., Ljung K. (2009) An auxin gradient and maximum in the Arabidopsis root apex shown by high-resolution cell-specific analysis of IAA distribution and synthesis. The Plant Cell, 21, 1659-1668.

Petrášek J., Mravec J., Bouchard R., Blakeslee J.J., Abas M., Seifertová D., Wiśniewska J., Tadele J., Čovanová M., Dhonukshe P., Skůpa P., Benková E., Perry L., Křeček P., Lee O.R., Fink G.R., Geisler M., Murphy A.S., Luschnig C., Zažímalová E., Friml J. (2006) PIN proteins perform a rate-limiting function in cellular auxin efflux. Science, 312, 914-918.

Pollmann S., Müller A., Piotrowski M., Weiler E.W. (2002) Occurrence and formation of indole-3-acetamide in Arabidopsis thaliana. Planta, 216, 155-161.

Rahman A., Takahashi M., Shibasaki K., Wu S., Inaba T., Tsurumi S., Baskin T.I. (2010) Gravitropism of Arabidopsis thaliana roots requires the polarization of PIN2 toward the root tip in meristematic cortical cells. The Plant Cell, 22, 1762-1776.

Rashotte A.M., Brady S.R., Reed R.C., Ante S.J., Muday G.K. (2000) Basipetal auxin transport is required for gravitropism in roots of Arabidopsis. Plant Physiology, 122, 481-490.

Rashotte A.M., DeLong A., Muday G.K. (2001) Genetic and chemical reductions in protein phosphatase activity alter auxin transport, gravity response, and lateral root growth. The Plant Cell, 13, 1683-1697.

Raven J.A. (1975) Transport of indole-3-acetic acid in plant cells in relation to $\mathrm{pH}$ and electrical potential gradients, and its significance for polar IAA transport. New Phytologist, 74, 163-172. 
Rayle D.L., Cleland R.E. (1992) The acid growth theory of auxin-induced cell elongation is alive and well. Plant Physiology, 99, 1271-1274.

Rayle D.L., Zenk M.H. (1973) Cell extension growth: some recent advances. Biochemical Society Symposium, 38, 235-246.

Rayle D.L., Haughton P.M., Cleland R. (1970) An in vitro system simulates plant cell extension growth. Proceedings of the National Academy of Sciences of the United States of America, 67, 1814-1817.

Rosquete M.R., Barbez E., Kleine-vehn J. (2012) Cellular auxin homeostasis: gatekeeping is housekeeping. Molecular Plant, 5, 772-786.

Rubery P.H., Sheldrake A.R. (1973) Effect of pH and surface charge on cell uptake of auxin. Nature New Biology, 244, 285-288.

Ruzicka K., Strader L.C., Bailly A., Yang H., Blakeslee J., Langowski L., Nejedlá E., Fujita H., Itoh H., Syono K., Hejátko J., Gray W.M., Martinoia E., Geisler M., Bartel B., Murphy A.S., Friml J. (2010) Arabidopsis PIS1 encodes the ABCG37 transporter of auxinic compounds including the auxin precursor indole-3-butyric acid. Proceedings of the National Academy of Sciences of the United States of America, 107, 10749-10753.

Santelia D., Vincenzetti V., Azzarello E., Bovet L., Fukao Y., Duchtig P., Mancuso S., Martinoia E., Geisler M. (2005) MDR-like ABC transporter AtPGP4 is involved in auxin-mediated lateral root and root hair development. FEBS Letters, 579, 5399-5406.

Schlicht M., Strnad M., Scanlon M.J., Mancuso S., Hochholdinger F., Palme K., Volkmann D., Menzel D., Baluska F. (2006) Auxin immunolocalization implicates vesicular neurotransmitter-like mode of polar auxin transport in root apices. Plant Signaling \& Behavior, 1, 122-133.

Shi L., Miller I., Moore R. (1993) Immunocytochemical localization of indole-3-acetic acid in primary root of Zea mays. Plant, Cell \& Environment, 16 967-973.

Swarup R., Péret B. (2012) AUX/LAX family of auxin influx carriers - an overview. Frontiers in plant science, 3, 225.

Swarup K., Benková E., Swarup R., Casimiro I., Péret B., Yang Y., Parry G., Nielsen E., De Smet I., Vanneste S., Levesque M.P., Carrier D., James N. Calvo V., Ljung K., Kramer E., Roberts R., Graham N., Marillonnet S., Patel K., Jones J.D., Taylor C.G., Schachtman D.P., May S., Sandberg G., Benfey P., Friml J., Kerr I., Beeckman T., Laplaze L., Bennett M.J. (2008) The auxin influx carrier LAX3 promotes lateral root emergence. Nature Cell Biology, 10, 946-954.

Terasaka K., Blakeslee J.J., Titapiwatanakun B., Peer W.A., Bandyopadhyay A., Makam S.N., Lee O.R., Richards E.L., Murphy A.S., Sato F., Yazaki K. (2005) PGP4, an ATP binding cassette P-glycoprotein, catalyzes auxin transport in Arabidopsis thaliana roots. The Plant Cell, 17, 2922-2939.

Tsuda E., Yang H., Nishimura T., Uehara Y., Sakai T., Furutani M., Koshiba T., Hirose M., Nozaki H., Murphy A.S., Hayashi K. (2011) Alkoxy-auxins are selective inhibitors of auxin transport mediated by PIN, ABCB, and AUX1 transporters. Journal of Biological Chemistry, 286, 2354-2364.

Tsurumi S., Ohwaki Y. (1978) Transport of ${ }^{14} \mathrm{C}$-labeled indoleacetic acid in Vicia root segments. Plant and Cell Physiology, 19, 1195-1206.

Ulmasov T., Murfett J., Hagen G., Guilfoyle T. (1997) Aux/IAA proteins repress expression of reporter genes containing natural and highly active synthetic auxin response elements. The Plant Cell, 9, 1963-1971.

Utsuno K., Shikanai T., Yamada Y., Hashimoto T. (1998) AGR, an agravitropic locus of Arabidopsis thaliana, encodes a novel membrane-protein family member. Plant and Cell Physiology, 39, 1111-1118.

Wan Y., Jasik J., Wang L., Hao H., Volkmann D. Menzel D., Mancuso S., Baluška F., Lin J. (2012) The signal transducer NPH3 integrates the phototropin1 photosensor with PIN2-based polar auxin transport in Arabidopsis root phototropism. The Plant Cell, 24, 551-565.

Wang B., Bailly A., Zwiewka M., Henrichs S., Azzarello E., Mancuso S., Maeshima M., Friml J., Schulz A., Geisler M. (2013) Arabidopsis TWISTED DWARF1 functionally interacts with auxin exporter $\mathrm{ABCB} 1$ on the root plasma membrane. The Plant Cell, doi: 10.1105/tpc.112.105999.

Went F.W. (1974) Reflections and speculations. Annual Review of Plant Physiology, 25, 1-26.

Wisniewska J., Xu J., Seifertová D., Brewer P.B., Ruzicka K., Blilou I., Rouquié D., Benková E., Scheres B., Friml J. (2006) Polar PIN localization directs auxin flow in plants. Science, 312, 883.

Wu G., Otegui M.S., Spalding E.P. (2010) The ERlocalized TWD1 immunophilin is necessary for localization of multidrug resistance-like proteins required for polar auxin transport in Arabidopsis roots. The Plant Cell, 22, 3295-3304.

Yang H., Murphy A.S. (2009) Functional expression and characterization of Arabidopsis ABCB, AUX 1 and PIN auxin transporters in Schizosaccharomyces pombe. The Plant Journal, 59, 179-191.

Young L.M., Evans M.L., Hertel R. (1990) Correlations between gravitropic curvature and auxin movement across gravistimulated roots of Zea mays. Plant Physiology, 92, 792-796.

Zažímalová E., Murphy A.S., Yang H., Hoyerová K., Hošek P. (2009) Auxin transporters - Why So Many? Cold Springs Harbor Perspectives in Biology, 2, a001552-a001552. 